\title{
Context-US Learning in Aplysia californica
}

\author{
Ruth M. Colwill, Robin A. Absher, and Mavis L. Roberts \\ Howard Hughes Medical Institute, Center for Neurobiology and Behavior, Columbia University, College of Physicians and \\ Surgeons, New York, New York 10032
}

\begin{abstract}
Two experiments explored learning about the relation between an unconditioned stimulus (US) and the context in which that US was delivered in Aplysia californica. Subjects were exposed to 2 different contexts. They received a series of moderate electric shock USs in one context but not in the other. Experiment 1 revealed that the context-shock pairings were sufficient to establish an association between that context and the shock. That association was demonstrated by the ability of the reinforced context to enhance a defensive reflex and to reduce learning about a conditioned stimulus (CS) that was subsequently paired with the shock US. Experiment 2 provided evidence that the context-US association could be extinguished by simple nonreinforced exposure to the reinforced context. These results show that context conditioning is not unique to vertebrate learning. We argue that this learning is difficult to accommodate within current contiguity-based neuronal models of learning.
\end{abstract}

Experimental investigations of the associative capacities of invertebrates have tended to focus on learning yielded by pairings of conditioned (CS) and unconditioned stimuli (US), so-called Pavlovian conditioning (e.g., Quinn et al., 1974; Couvillon and Bitterman, 1980, 1982; Carew et al., 1981, 1983; Sahley et al., 1981; Walters et al., 1981; Alkon, 1983; Bitterman et al., 1983). Relatively little attention, however, has been given to learning about the environmental context in which those CS-US pairings take place. This neglect is somewhat surprising for 2 reasons. First, abundant evidence has accumulated that both birds and mammals can learn about the relations obtaining between contexts and a variety of events, including both CSs and USs, that are embedded within those contexts (e.g., Balsam and Schwartz, 1981; Marlin, 1982; Rescorla, 1984; Rescorla et al., 1984). Second, modern theories of Pavlovian conditioning have increasingly acknowledged an important role for contextual stimuli (e.g., Rescorla and Wagner, 1972; Gibbon and Balsam, 1981; Wagner, 1981; Miller and Schachtman, 1984). Indeed, several complex learning phenomena are thought to depend on the development of associations between the contextual stimuli and the events that occur in their presence.

The observation that vertebrate learning is exquisitely sen-

\footnotetext{
Received May 4, 1987; revised Apr. 21, 1988; accepted Apr. 22, 1988

This research was supported by funds from the Howard Hughes Medical Institute. We should like to thank M. Morris for the provision of healthy subjects and J. Sliney for his excellent care of our subjects. We are also indebted to our many colleagues for their helpful comments and enthusiastic support during the conduct of this work and in preparation of the manuscript. In particular, we are extremely grateful to Greg Clark, Randy Gallistel, Eric Kandel, Robert Rescorla, and Saul Sternberg.

Correspondence should be addressed to Dr. Ruth M. Colwill, Department of Psychological Sciences, Purdue University, West Lafayette, IN 47907.

Copyright (C) 1988 Society for Neuroscience $0270-6474 / 88 / 124434-06 \$ 02.00 / 0$
}

sitive to the actual contingency between the CS and the US frequently receives explanation in terms of context conditioning. It has been well documented that simply arranging CS-US contiguities is not by itself sufficient to produce conditioning of that CS. Rather, in order for such learning to occur, the CS must be predictive of the occurrence of the US. In other words, there has to be a positive contingency between the CS and the US. Thus, pairings of a CS and a US will be less effective if the US is also scheduled to occur in the absence of that CS (e.g., Rescorla, 1968; Dweck and Wagner, 1970; Gamzu and Williams, 1973). One explanation for the finding that conditioning of the CS is reduced by degrading the CS-US contingency is that the USs occurring without the CS condition the contextual stimuli. Because those contextual stimuli are present on the occasions that the CS is paired with the US, the US is predicted by the context and therefore rendered less effective as a reinforcer for the CS. The ability of one signal to prevent learning about another because of its own association with the US is called blocking (Kamin, 1968, 1969). This phenomenon has been taken as evidence that for learning to occur, the CS must provide information about the occurrence of the US that is otherwise unavailable. That idea has been extremely influential in shaping modern theories of Pavlovian conditioning (Rescorla and Wagner, 1972; Mackintosh, 1975).

Not only have contextual associations been invoked to account for sensitivity to the CS-US contingency, but they have also been invoked to explain the detrimental effects of CS and US preexposure on subsequent conditioning involving those events. Given the theoretical importance that has been attached to contextual conditioning, it seems natural to ask whether invertebrates are also capable of forming similar associations. Furthermore, it would seem especially valuable to demonstrate such learning in those preparations that have been used for neurophysiological analyses of learning. Clearly, their virtue as model systems for vertebrate learning would be enhanced by further demonstrations of similarities between their learning repertoires and those of vertebrates, whose own nervous systems are less amenable to neurophysiological analysis. Several invertebrate systems have yielded favorably to a neuronal analysis of learning, including, for example, Aplysia and Hermissenda (e.g., Quinn, 1984; Farley and Alkon, 1985; Byrne, 1987). The experiments described in this paper focus on one of these invertebrates, the marine mollusc Aplysia californica, for which a promising start has already been made in the biochemical and neurophysiological investigation of Pavlovian conditioning (e.g., Hawkins et al., 1983; Clark, 1984).

The 2 studies reported here examine whether Aplysia californica could form associations between a conventional US and the context in which that US was presented. Experiment 1 demonstrated that such associations could be acquired. Experiment 
2 revealed that these context-US associations can also be extinguished by simple nonreinforced exposure to the context after conditioning.

\section{Experiment 1}

The purpose of this experiment was to determine whether an invertebrate, Aplysia californica, could learn about the relation obtaining between an aversive US and the context in which that US occurred. To this end, subjects were exposed daily to 2 very different contexts. One context was a smooth, round bowl containing lemon-flavored seawater. The other was a rectangular chamber with a ridged surfacc containing unscented seawater that was gently vibrated by an aerator located in one corner. Each subject received several moderate electric shocks applied to its mantle shelf in one context but not in the other. The extent to which this treatment was successful in conditioning the context was assessed in 2 ways: first, by the degree to which the reinforced context influenced a defensive reaction; and second, by its ability to interfere with learning about a discrete, punctate CS paired with a US.

One strategy that has been used to reveal associations between a context and aversive USs in rats has been to measure behaviors associated with fear, such as the suppression of appetitively motivated responses (Dweck and Wagner, 1970; Randich and LoLordo, 1979a, b; Baker et al., 1981). The general idea is that the incidence of such behaviors should be elevated in an environment that has a history of pairings with the aversive events. For the present purposes, we decided to measure the duration of siphon withdrawal in response to the application of a mild tactile stimulus to the siphon. Elsewhere, it has been established that withdrawal of the siphon is one component of Aplysia's defensive withdrawal reflex elicited by noxious stimuli (Pinsker et al., 1970). It was anticipated that the duration of siphon withdrawal in response to the stimulation should be enhanced in the context that had been paired with shock compared with the nonreinforced context. This technique has been used to reveal associations between Pavlovian CSs and aversive USs in both rats (Brown et al., 1951) and Aplysia (Walters et al., 1981).

The second assessment procedure exploited another finding that has been well established in vertebrates: Pairings of a CS and a US are less effective when delivered in a context that has previously been associated with that US (Tomie, 1976, 1981; Randich and LoLordo, 1979b; Baker and Mercier, 1982; Rescorla et al., 1984). Thus, all subjects were given a series of conditioning trials in which a tactile CS delivered to the siphon signaled the presentation of a shock US to the mantle shelf. For half the animals, these conditioning trials took place in the context that had previously been paired with that shock US; for the remaining animals, those pairings were presented in the nonreinforced context. In order to obtain a measure of CS-US learning that was uncontaminated by potential differences in the effects of the 2 contexts on performance to that CS, subjects were tested in a common third environment, the home tank. It was predicted that conditioning to the CS, as indexed by the duration of siphon withdrawal elicited by that CS, would be better if the CS-US pairings occurred in the nonreinforced context.

\section{Materials and methods}

Subjects. The subjects were 16 experimentally naive Aplysia californica obtained from Sea Life Supply (Sand City, CA). One animal died during the course of the experiment, and its data were therefore eliminated.
Subjects were housed in individual perforated pans $(20 \times 20 \times 10 \mathrm{~cm})$ that floated freely in a 200 gallon capacity tank of filtered and aerated artificial seawater (Instant Ocean) kept between 15 and $16^{\circ} \mathrm{C}$. The subjects weighed approximately $125 \mathrm{gm}$ at the start of the study and were maintained on a diet of laver (dried seaweed). They were fed daily about an hour after the completion of experimental procedures. Uneaten food was removed the next morning before the start of any experimental procedures. One week prior to the start of the experiment, the animals were anesthetizcd by immersion in icy $\left(1-3^{\circ} \mathrm{C}\right)$ salt-water, and their parapodia were excised in order to provide an unobstructed view of and access to the siphon and mantle shelf.

Apparatus. Two discriminably different contexts were used. One context, Context $\mathrm{A}$, consisted of a smooth, round, white plastic bowl containing a mixture of $200 \mathrm{ml}$ of artificial seawater (Instant Ocean) and 1 $\mathrm{ml}$ of Durkee brand lemon extract. The other context, Context B, was a dark gray, rectangular chamber measuring $18.5 \times 13 \times 9.5 \mathrm{~cm}$ filled with artificial seawater (Instant Ocean). Its surface consisted of a series of narrow ridges about $0.3 \mathrm{~cm}$ wide, spaced $0.3 \mathrm{~cm}$ apart. An aerator was mounted in one corner to provide a localized source of mild turbulence and to increase the oxygen content of the seawater.

The tactile stimulus used to stimulate the siphon in both assessment tests was a $14.5-\mathrm{cm}$-long wooden cocktail stick tapered to a fine point. The tapercd cnd was inserted manually into the funnel of the siphon, and the tip was drawn gently but swiftly along about $1 \mathrm{~cm}$ of the siphon skin. The US was an $80 \mathrm{~mA}, 60 \mathrm{~Hz}$ AC shock delivered through capillary electrodes that were applied manually to the surface of the mantle shelf.

Procedure. Each subject was exposed for $20 \mathrm{~min}$ daily to each of the 2 contexts. The 2 exposures were separated by an interval of at least 5 $\mathrm{hr}$, and the order of exposure to the 2 contexts was balanced. In one of the contexts, subjects received 4 shock USs per day for $8 \mathrm{~d}$. The shocks were distributed randomly both within and across sessions. In the other context, there were no programmed events. For half the subjects, Context $A$ served as the reinforced context and Context $B$ as the nonreinforced context; for the remaining subjects, this arrangement was reversed. On the first day of conditioning, all subjects inked profusely in response to the first shock US. Because of reduced visibility, each subject was transferred to an identical but uncontaminated context. The amount of ink released in subsequent conditioning sessions was sufficiently small that it was not necessary to move the animals.

Twenty-four hours after completion of the differential conditioning treatment, the associative value of the contexts was assessed through their impact on the duration of a defensive reflex. An experimenter blind to the conditioning histories of the animals applied the tactile stimulus to the siphon in both contexts and measured the time from onset of siphon stimulation to complete relaxation of the siphon. To reduce any disruptive effects of recent handling on the siphon withdrawal reflex, the test was administered no sooner than 2 min after the subjects had been placed in the context. The test session terminated after 20 min, and the subjects were returned to their home tank. All subjects were tested first in Context $\mathrm{A}$ and then, $5 \mathrm{hr}$ later, in Context B. Thus, half the subjects received their first test in the context in which shocks had occurred, and half received their first test in the nonreinforced context. In order to preserve the experimental blind, no shocks were delivered during the test sessions.

Investigation of the effect of contextual conditioning on CS-US learning began the following day. First, all subjects were tested for their reaction to stimulation of the siphon with the tactile CS in their home tank. An experimenter measured the time from application of the tactile stimulus to complete relaxation of the siphon. These pretest scores were used to divide the animals into 2 matched groups balanced with respect to identity of the reinforced context. Each group received two $20 \mathrm{~min}$ conditioning sessions in one context. For one group of animals $(n=7)$, the conditioning trials occurred in the context previously paired with shock; for the other group $(n=8)$, the conditioning trials were given in the nonreinforced context. The conditioning sessions were spaced 24 $\mathrm{hr}$ apart, and each contained 4 CS-US pairings with a variable intertrial interval. Both the CS and the US were administered by hand with an interstimulus interval of approximately $0.5 \mathrm{sec}$. The experimenter who gave the conditioning trials did not know which animal belonged to which group. In order to obtain a measure of the effect of context value on learning uncontaminated by its effect on performance, all subjects were tested $24 \mathrm{hr}$ later in their home tank. An experimenter blind to the treatment of the animals administered one nonreinforced presentation of the tactile CS to each subject and measured the duration of siphon withdrawal. 


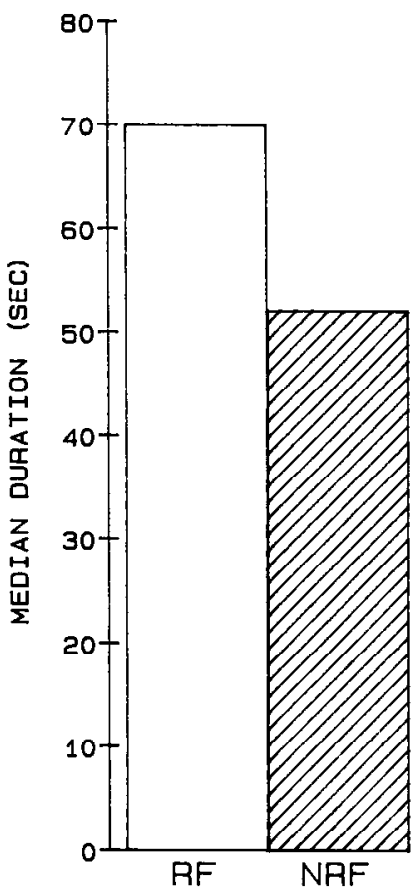

Figure 1. Experiment 1. Median duration of siphon withdrawal in response to mild tactile siphon stimulation in a context that had either been paired with shock (open bar) or not (striped bar).

\section{Results and discussion}

Figure 1 shows the median duration of siphon withdrawal in the reinforced and nonreinforced contexts obtained during the initial test sessions. It is clear that withdrawal was prolonged in the context previously paired with the shock US compared with the nonshocked context [Wilcoxon $T(15)=13, p<0.01$ ]. That outcome is consistent with the view that the animals had learned in which context shocks were scheduled to occur.

Figure 2 displays the results obtained during the nonreinforced presentations of the tactile CS given in the home tank before (pretest) and after (posttest) CS-US conditioning. The pair of bars on the left shows the median duration of siphon withdrawal prior to conditioning. Although the duration of siphon withdrawal was slightly longer in the group that was to be conditioned in the nonreinforced context, the difference was not significant. The pair of bars on the right shows the results of the postconditioning test. For both groups, responding to the CS increased. That increase was significant for the group conditioned in the nonreinforced context $[T(8)-0, p<0.01]$ but not for the group conditioned in the reinforced context; moreover, that increase was of a considerably greater magnitude in the group conditioned in the nonreinforced context [MannWhitney $U(7,8)=12.5, p<0.05$, 1-tailed]. Despite the substantial variability across animals in duration of siphon withdrawal that makes this kind of between-subjects comparison inherently less sensitive than the within-subjects analyses used elsewhere in this study, there is a clear suggestion that the initial pairings of a context with shock established a context-shock association which then interfered with learning about the CSshock relation.

This experiment provides 2 pieces of evidence that Aplysia can learn about context-US associations. First, subjects displayed a heightened defensive reflex in the context that had a history of pairings with shock. The specificity of that enhance-

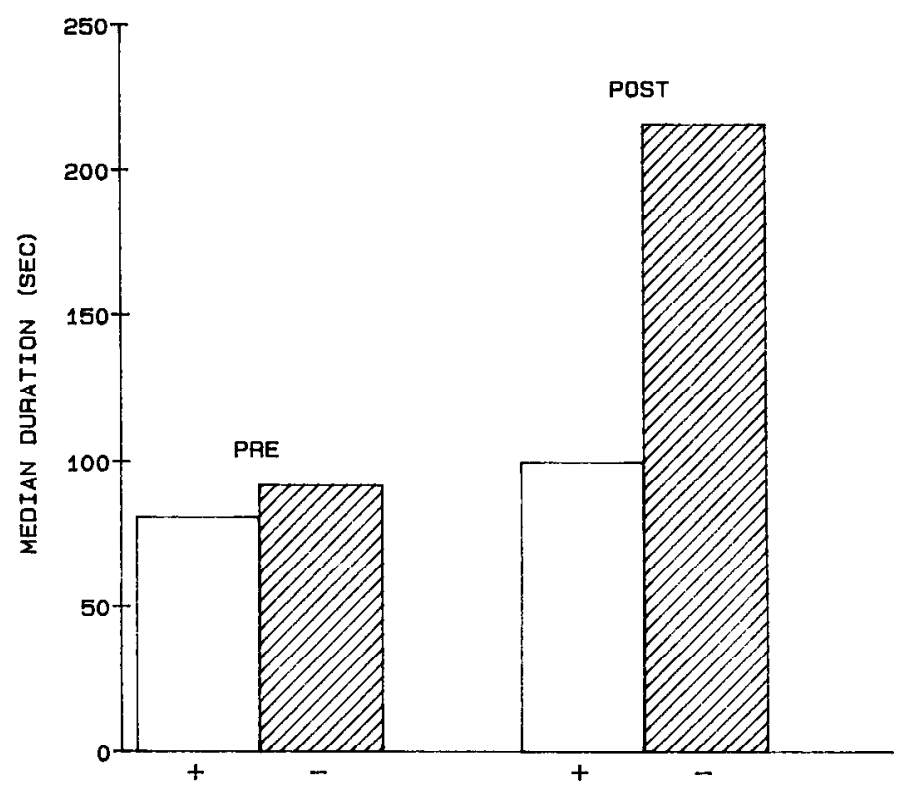

Figure 2. Experiment 1. Median duration of siphon withdrawal in response to mild tactile siphon stimulation delivered in the home tank. Scores are shown separately for the group conditioned in the reinforced context (open bars) and the group conditioned in the nonreinforced context (striped bars). The pretest scores obtained prior to conditioning are displayed on the left and the posttest scores obtained after conditioning are displayed on the right.

ment is extremely important because it rules out the possibility that the animals were simply sensitized by the shock US. Second, lcarning about a CS-US relation was impaired when that conditioning took place in the reinforced context. Although the magnitude of this effect was statistically rather modest, it is in the direction predicted by all current theoretical models of associative learning and therefore merits serious consideration.

It is of special interest to note that this second measure may be of theoretical significance because it provides the first suggestion of blocking in Aplysia. As we mentioned previously, blocking refers to the finding that conditioning of a CS will be less effective if the conditioning trials take place in the presence of another well-conditioned stimulus. Because this is one of the first demonstrations of blocking in Aplysia, it is important to note its limitations. It has several shortcomings shared by most vertebrate blocking experiments. First, comparison is made between the amounts of conditioning achieved when a CS is paired with a US in the presence of 2 stimuli that differ in their conditioning history. But it is, in fact, not possible to determine whether conditioning of the CS was attenuated by pairing in an excitatory context or conditioning of the CS was augmented by pairing in the nonreinforced control context. It may be that the nonreinforced context, by virtue of its negative relation to the US, develops inhibitory properties that promote conditioning of the CS. Analogous effects are known to occur in simple Pavlovian conditioning procedures: Both Rescorla (1971) and Wagner (1971) have reported that learning about a CS-US pairing is enhanced when that CS was accompanied by an inhibitory CS during conditioning. The presence of the inhibitor is thought to render the US especially "surprising" and thus promote its effectiveness as a reinforcer for the to-be-conditioned stimulus. For the present purposes, however, the important conclusion is that the 2 contexts differ in their action, thereby indicating successful discriminative conditioning of the contexts. Second, con- 
ditioning of the CS is inferred from responding in the test environment. It is possible that this test environment may be more similar to the nonshocked context than to the shocked context because it, too, had never been explicitly paired with shock. Consequently, it is possible that the conditioned effects of the CS transferred to the test environment better from the nonreinforced context than from the reinforced context. This difficulty is not unique to the present study but is present in almost all blocking experiments.

A difficulty more peculiar to the present experiments arises from the fact that the US was administered manually during conditioning. Although this was done "blind," it is possible that the animal's behavior differed in the shocked and nonshocked contexts, thereby influencing the actual delivery of the US. Although we have never observed systematic general behavioral differences in shocked and nonshocked contexts, such a possibility is difficult to rule out. However, even if there were such subtle influences on the US delivery, they would in turn depend on the animal learning which context contained shock. It is just the occurrence of that learning that is the principal conclusion of the experiment. Consequently, regardless of whether these data demonstrate blocking in the sense that blocking is observed in the vertebrate literature, they do imply that the animals learned in which context the shock USs were due to occur.

\section{Experiment 2}

The intention of this experiment was to examine the effects of nonreinforced exposure to a context that had previously been paired with shock. The typical finding in the vertebrate literature is that this type of treatment is successful in extinguishing the association between the context and the US (Baker et al., 1981; LoLordo and Randich, 1981; Rescorla et al., 1984). It was of interest to ask whether similar results would be obtained with Aplysia. Subjects were given a differential conditioning treatment to 2 contexts: One context was paired with shock, whereas the other context was never reinforced. Then, half the animals were simply placed in the reinforced context but no shocks were delivered. It was anticipated that this treatment would attenuate, if not completely abolish, the context-US association. This prediction was tested using the first, more sensitive within-subjects assessment procedure of the previous experiment. The siphon was gently stimulated in each of the 2 contexts. The duration of siphon withdrawal in response to that stimulation was expected to be of a similar magnitude in the 2 contexts.

Because the extinction treatment itself required a period of 2 $\mathrm{d}$, we wanted to be sure that if no differential effect were obtained it would not be due to the simple passage of time. Although retention of associations has been reported in other situations, it was not known whether the context-US association would survive the interval between training and testing in the present case. Thus, to control for any loss due to forgetting, a second group of animals was also tested. These animals simply remained in their home tank during the period of extinction administered to the other animals. It was expected that the differential response would be observed in these animals: Siphon withdrawal would be longer in the reinforced than in the nonreinforced context.

\section{Materials and methods}

Subjects and apparatus. Thirty-two experimentally naive Aplysia californica obtained from Sea Life Supply (Sand City, CA) served as subjects. Details of housing, maintenance, and surgical procedures were as

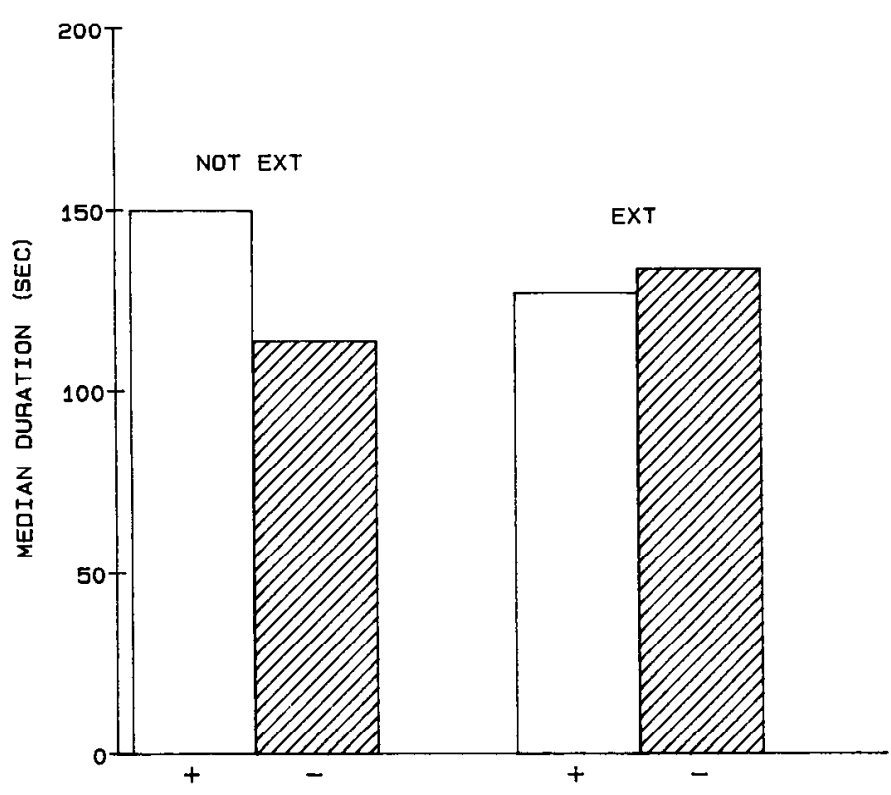

Figure 3. Experiment 2. Median duration siphon withdrawal in the context paired with shock (open bars) and in the nonshocked context (striped bars) without extinction (left-hand side) and with extinction of the reinforced context (right-hand side).

for Experiment 1. The apparatus was the same as that used in Experiment 1.

Procedure. This experiment was run in 2 replications with 16 animals in each. The procedure used to establish context-US associations was identical to that described for Experiment 1. Differential conditioning, however, was continued for a total of $12 \mathrm{~d}$. The identity of the context paired with shock was balanced across animals.

Following completion of context discrimination training, the subjects were divided into 2 groups balanced with respect to the identity of the reinforced context. One group received two $40 \mathrm{~min}$ exposures to the previously reinforced context on each of $2 \mathrm{~d}$, once in the morning and once in the afternoon. No shocks were administered during this phase of the experiment. The other group was left undisturbed in the home tank. These control animals were not handled because it seemed difficult to guarantee equivalent handling by an experimenter who per force knew whether or not the animals' behavior was to be extinguished. This strategy is routinely adopted in vertebrate studies that involve conditioning manipulations of the context (e.g., Wagner, 1976; Baker and Mercier, 1982a; Schachtman et al., 1987).

The day after the last extinction session, all subjects were tested for their reaction to the tactile CS applied to the siphon in each of the 2 contexts. Again, all animals were first tested in Context A by an experimenter blind to the experimental treatments of the animals who also measured the duration of siphon withdrawal. The test was repeated 5 $\mathrm{hr}$ later in Context B.

\section{Results and discussion}

The results of the test sessions are shown separately for the reinforced and nonreinforced contexts in Figure 3. On the lefthand side are shown the median siphon withdrawal scores for the group that received no extinction treatment. Siphon withdrawal in response to application of the tactile CS was significantly longer in the reinforced context than in the nonreinforced context $[T(16)=28, p<0.05]$. The data for the group that received extinction of the reinforced context are plotted on the right-hand side of Figure 3. There was no evidence of differential responding to the tactile $\mathrm{CS}$ in the 2 contexts $[T(16)=55, p>$ $0.10]$. The median difference in siphon duration between the 2 contexts was $51 \mathrm{sec}$ in the nonextinguished group and $-20 \mathrm{sec}$ in the extinguished group. Statistical analysis of these differences 
indicated that the difference in responding in the 2 contexts was significantly larger in the nonextinguished than in the extinguished condition [Mann-Whitney $U(16,16)=82, p<0.05$, l-tailed].

Two comments should be made about these results. First, the differential performance of the nonextinguished group to the tactile CS replicates that observed in Experiment 1. Moreover, that difference was detected $2 \mathrm{~d}$ after the final session of discrimination training, indicating that context-US learning is quite robust. It is not possible in this study to evaluate whether some "forgetting" actually occurred. Comparison of the magnitude of this difference with that obtained in Experiment 1 is obviously precluded by the fact that, for whatever reason, the differences are obtained at very different points on the measurement scale.

The second point of interest is that the results for the extinction group indicate that nonreinforced exposure to the reinforced context was sufficient to eliminate the context-US association. This observation is consistent with reports that repeated nonreinforced exposure to a CS results in a decline in conditioned responding in Aplysia (Carew et al., 1981). However, a unique feature of the present study is the inclusion of a control for forgetting. The loss in context discrimination that we observe can therefore be unequivocally attributed to the extinction procedure per se rather than to the simple passage of time.

\section{General Discussion}

Recent work indicates that the range of associative abilities of Aplysia californica is quite broad. There is evidence not only for Pavlovian conditioning but also for instrumental learning (Hawkins et al., 1985; Cook and Carew, 1986). This paper provides a demonstration of another instance of associative learning in Aplysia, namely, contextual conditioning. Pairings of a shock US with one context led to the development of an association between that US and the context. That association was revealed in 2 ways: first, by an enhanced defensive reflex in the reinforced context; and second, by the ability of the reinforced context to reduce learning about a CS-US relation. Furthermore, this context-US learning was observed to be retained for more than 48 hr. Finally, it was found that the context-US association would also undergo extinction. Nonreinforced exposure to the context following conditioning was sufficient to eliminate any evidence of a context-US association. Apparently, context-US learning is not limited to the cognitive repertoire of mammals and birds but forms part of the associative abilities of at least one invertebrate.

The contexts used in these studies differed on a number of stimulus dimensions, including texture, shape, and odor. Unpublished work in our laboratory indicates that Aplysia can discriminate between different surface textures and between different odors. Walters et al. (1981) have also shown that chemosensory stimuli can serve as signals for aversive shock in Aplysia. Subsequent research, however, will be required to discover which features of the present contexts were selected for association with the US. It will also be of interest to ask whether similar associations can be formed between CSs and the contexts in which they occur.

One potentially important implication of the present findings concerns the mechanism by which contingencies are detected between events in Pavlovian conditioning. It has been reported that additional unsignaled presentations of the US will weaken conditioning to a CS paired with that US in Aplysia (Hawkins et al., 1986). That observation has been confirmed in our laboratory. We have already mentioned the account that is usually entertained for this effect in vertebrate learning: The additional USs condition the context so that it can block learning about CSs conditioned in its presence. The fact that such associations can be learned by Aplysia raises the intriguing possibility that conditioning of the context may also mediate the sensitivity to CS-US contingency reported for Aplysia. Until now, it has seemed more plausible to ascribe the contingency effects to nonassociative processes. Specifically, the effectiveness of the US on conditioning trials is thought to be reduced because the additional presentations of the US lead to habituation of the US (Hawkins et al., 1986). Empirical techniques that can be used to separate these alternatives have been devised for vertebrates (see Durlach, 1983).

Finally, it is worth commenting on the implications of these results for the neuronal models of conditioning that have been developed to account for Pavlovian conditioning in Aplysia. These models are, for the most part, derived from the results of experiments using as the CS mild, punctate stimulation of sensory neurons of either the tail (Walters and Byrne, 1983) or the siphon (Hawkins et al., 1983; Hawkins and Kandel, 1984) and using noxious electric shock to the tail as the US. One of the most striking features of such models is their reliance on strict temporal contiguity between the CS and the US in order to obtain associative effects. Briefly, it is assumed that the cascade of biochemical and molecular events triggered by the US is rendered more effective if it is shortly preceded by spike activity in the sensory neuron activated by presentation of the CS. This mechanism of activity-dependent neuromodulation (Walters and Byrne, 1983) or activity-dependent amplification of presynaptic facilitation (Hawkins et al., 1983) requires that presentation of the CS produce some activation of its sensory neuron(s). Because our studies on contextual conditioning have shown that associations can be formed between a US and static cues that are continuously present, they raise the possibility that different cellular mechanisms may be involved in different associative learning paradigms. To preserve the present cellular models, it would have to be argued that continuous exposure to the contextual stimuli does not result in complete habituation to those stimuli. Consequently, the context sensory neurons would display spike activity prior to US presentations, thus allowing operation of the mechanism of activity-dependent enhancement. However, an interesting problem arises even if we are to grant the context sensory neurons this unusual property. Although one could now obtain conditioning with a mechanism of activity-dependent enhancement, the context-US association should undergo extinction during the periods of extended nonreinforcement when the US is absent. This problem highlights the need for an adequate theory of extinction. Of course, the physiological mechanism underlying context-US learning need not be the same as that identified for discrete CS-US learning. However, the behavioral data have indicated some similarity between the rules that govern the formation of CS-US associations and those that apply to context-US learning (see Balsam and Tomie, 1985). It would be attractive to find a similar parallel at the neurophysiological level.

\section{References}

Alkon, D. L. (1983) Learning in a marine snail. Sci. Am. 249: 70.

Baker, A. G., and P. Mercier (1982a) Manipulation of the apparatus and response context may reduce the US pre-exposure interference effect. Q. J. Exp. Psychol. 34B: 221-234. 
Baker, A. G., and P. Mercier (1982b) Prior experience with the conditioning events: Evidence for a rich cognitive representation. In Quantitative Analyses of Behavior: Acquisition, Vol. 3, M. L. Commons, R. J. Herrnstein, and A. Wagner, eds., pp. 117-143, Ballinger, Cambridge, MA.

Baker, A. G., P. Mercier, J. Gabel, and P. A. Baker (1981) Contextual conditioning and the US preexposure effect in conditioned fear. $J$. Exp. Psychol. Anim. Behav. Processes 7: 109-128.

Balsam, P. D., and A. Schwartz (1981) Rapid background conditioning in autoshaping. J. Exp. Psychol. Anim. Behav. Processes 1: 382-393.

Balsam, P. D., and A. Tomie, eds. (1985) Context and Learning. Erlbaum, Hillsdale, NJ.

Bitterman, M. E., R. Menzel, A. Fietz, and S. Schafer (1983) Classical conditioning of proboscis extension in honeybees (Apis mellifera). J. Comp. Psychol. 97: 107-1 19.

Brown, J. S., H. I. Kalish, and I. E. Farber (1951) Conditioned fear as revealed by magnitude of startle response to an auditory stimulus. J. Exp. Psychol. 41: 317-328.

Byrne, J. H. (1987) Cellular analysis of associative learning. Physiol. Rev. 67: 329-439.

Carew, T. J., E. T. Walters, and E. R. Kandel (1981) Classical conditioning in a simple withdrawal reflex in Aplysia californica. J. Neurosci. $1: 1426-1437$

Carew, T. J., R. D. Hawkins, and E. R. Kandel (1983) Differential classical conditioning of a defensive withdrawal reflex in Aplysia californica. Science 219: 397-400.

Clark, G. A. (1984) A cellular mechanism for the temporal specificity of classical conditioning of the siphon-withdrawal response in Aplysia. Soc. Neurosci. Abstr. 10: 268.

Cook, D. G., and T. J. Carew (1986) Operant conditioning of head waving in Aplysia. Proc. Natl. Acad. Sci. USA 83: 1120-1124.

Couvillon, P. A., and M. E. Bitterman (1980) Some phenomena of associative learning in honeybees. J. Comp. Physiol. Psychol. 94:878885.

Couvillon, P. A., and M. E. Bitterman (1982) Compound conditioning in honeybees. J. Comp. Physiol. Psychol. 96: 192-199.

Durlach, P. J. (1983) The effect of signalling intertrial USs in autoshaping. J. Exp. Psychol. Anim. Behav. Processes 9: 374-389.

Dweck, C. S., and A. R. Wagner (1970) Situational cues and correlation between CS and US as determinants of the conditioned emotional response. Psychonom. Sci. 18: 145-147.

Farley, J., and D. L. Alkon (1985) Cellular mechanisms of learning, memory, and information storage. Annu. Rev. Psychol. 36:419-494.

Gamzu, E. R., and D. R. Williams (1973) Associative factors underlying the pigeon's key pecking in autoshaping procedures. J. Exp. Anal. Behav. 19: 225-232.

Gibbon, J., and P. D. Balsam (1981) Spreading association in time. In Autoshaping and Conditioning Theory, C. M. Locurto, H. S. Terrace, and J. Gibbon, eds., pp. 219-253, Academic, New York.

Hawkins, R. D., and E. R. Kandel (1984) Is there a cell-biological alphabet for simple forms of learning? Psychol. Rev. 91: 375-391.

Hawkins, R. D., T. W. Abrams, T. J. Carew, and E. R. Kandel (1983) A cellular mechanism of classical conditioning in Aplysia: Activitydependent amplification of presynaptic facilitation. Science 219:400 405.

Hawkins, R. D., G. A. Clark, and E. R. Kandel (1985) Operant conditioning and differential classical conditioning of gill withdrawal in Aplysia. Soc. Neurosci. Abstr. 11: 796.

Hawkins, R. D., T. J. Carew, and E. R. Kandel (1986) Effects of interstimulus interval and contingency on classical conditioning of the Aplysia siphon withdrawal reflex. J. Neurosci. 6: 1695-1701.

Kamin, L. J. (1968) Attention-like processes in classical conditioning. In Miami Symposium on Predictability, Behavior, and Aversive Stimulation, M. R. Jones, ed., pp. 9-33, University of Miami Press, Coral Gables, FL.

Kamin, L. J. (1969) Predictability, surprise, attention and conditioning. In Punishment and Aversive Behavior, B. Campbell and R. Church, eds., pp. 279-296, Appleton-Century-Crofts, New York.

LoLordo, V. M., and A. Randich (1981) Effects of experience of electric shock upon subsequent conditioning of an emotional response: Associative and non-associative accounts. In Advances in Analysis of Behavior: Predictability, Correlation and Contiguity, Vol. 2, P. Harzem and M. Zeiler, eds., pp. 247-285, Wiley, New York.
Mackintosh, N. J. (1975) A theory of attention: Variations in the associability of stimuli with reinforcement. Psychol. Rev. 82: 276298.

Marlin, N. A. (1982) Within-compound associations between the context and the conditioned stimulus. Learn. Motiv. 13: 526-541.

Miller, R. R., and T. Schachtman (1985) The several roles of context at the time of retrieval. In Context and Learning, P. D. Balsam and A. Tomie, eds., pp. 167-194, Erlbaum, Hillsdale, NJ.

Pinsker, H., I. Kupfermann, V. Castellucci, and E. R. Kandel (1970) Habituation and dishabituation of the gill-withdrawal reflex in Aplysia. Science 167: 1740-1742.

Quinn, W. G. (1984) Work in invertebrates on the mechanisms underlying learning. In The Biology of Learning, P. Marler and H. S. Terrace, eds., pp. 197-246, Springer-Verlag, Berlin.

Quinn, W. G., W. A. Harris, and S. Benzer (1974) Conditioned behavior in Drosophila melanogaster. Proc. Natl. Acad. Sci. USA 71 . 708.

Randich, A., and V. M. LoLordo (1979a) Associative and non-associative theories of the UCS preexposure effect: Implications for Pavlovian conditioning. Psychol. Bull. 86: 523-548.

Randich, A., and V. M. LoLordo (1979b) Preconditioning exposure to the unconditioned stimulus affects the acquisition of a conditioned emotional response. Learn. Motiv. 10: 245-277.

Rescorla, R. A. (1968) Probability of shock in the presence and absence of CS in fear conditioning. J. Comp. Physiol. Psychol. 66: 1-5.

Rescorla, R. A. (1971) Variation in the effectiveness of reinforcement and nonreinforcement following prior inhibitory conditioning. Learn. Motiv. 2: 113-123

Rescorla, R. A. (1984) Associations between Pavlovian CSs and context. J. Exp. Psychol. Anim. Behav. Processes 10: 195-204.

Rescorla, R. A., and A. R. Wagner (1972) A theory of Pavlovian conditioning: Variations in the effectiveness of reinforcement and nonreinforcement. In Classical Conditioning II: Current Theory and Research, A. H. Black and W. F. Prokasy, eds., pp. 64-99, AppletonCentury-Crofts, New York.

Rescorla, R. A., P. J. Durlach, and J. W. Grau (1985) Contextual learning in Pavlovian conditioning. In Context and Learning, P. D. Balsam and A. Tomie, eds., pp. 23-56, Erlbaum, Hillsdale, NJ.

Sahley, C., J. W. Rudy, and A. Gelperin (1981) An analysis of associative learning in a terrestrial mollusc. I. Higher-order conditioning, blocking, and a transient US pre-exposure effect. J. Comp. Physiol. 144: $1-8$.

Schachtman, T. R., A. M. Brown, E. L. Gordon, D. A. Catterson, and R. R. Miller (1987) Mechanisms underlying retarded emergence of conditioned responding following inhibitory training: Evidence for the comparator hypothesis. J. Exp. Psychol. Anim. Behav. Processes 13: 310-322.

Tomie, A. (1976) Interference with autoshaping by prior context conditioning. J. Exp. Psychol. Anim. Behav. Processes 2: 323-334.

Tomie, A. (1981) Effects of unpredictable food upon the subsequent acquisition of autoshaping: Analysis of the context blocking hypothesis. In Autoshaping and Conditioning Theory, C. M. Locurto, H. S. Terrace, and J. Gibbon, eds., pp. 181-215, Academic, New York.

Wagner, A. R. (1971) Elementary associations. In Essays in Neobehaviorism: A Memorial Volume to Kenneth W. Spence, H. H. Kendler and J. T. Spence, eds., pp. 187-213, Appleton-Century-Crofts, New York.

Wagner, A. R. (1976) Priming in STM: An information processing mechanism for self-generated or retrieval-generated depression in performancc. In Habituation: Perspectives from Child Development, Animal Behavior, and Neurophysiology, T. J. Tighe and R. N. Leaton, eds., pp. 95-128, Erlbaum, Hillsdale, NJ.

Wagner, A. R. (1981) SOP: A model of automatic memory processing in animal behavior. In Information Processing in Animals: Memory Mechanisms, N. E. Spear and R. R. Miller, eds., pp. 1-47, Erlbaum, Hillsdale, $\mathrm{NJ}$.

Walters, E. T., and J. H. Byrne (1983) Associative conditioning of single neurons suggests a cellular mechanism for learning. Science 219: $405-408$

Walters, E. T., T. J. Carew, and E. R. Kandel (1981) Associative learning in Aplysia: Evidence for conditioned fear in an invertebrate. Science 211: 504-506. 